\title{
Pilot introduction of IWB and COWs in Greek schools
}

\author{
F. Foskolos, A. Vagelatos, Th. Komninos \\ Greek Ministry of Educations \& \\ R.A. Computer Technology Institute \\ Athens, Greece \\ foskolos, vagelat, komninos $\{@$ minedu.gov.gr $\}$
}

\begin{abstract}
This article focuses on the implementation of two pilot project for the introduction of ICT in Greek schools. These projects (introduction of IWB and COWs) are supposed to be the first steps of the implementation of "digital school" which is the government's strategy for ICT adoption in education. In the following, the key findings of the two projects are identified and improvements upon the selected process are discussed. Although there is insufficient evidence to identify the actual impact of these technologies upon learning due to limited time of their usage, the lessons learned from the managerial point of view are equally important.
\end{abstract}

Keywords: ICT in Education; Interactive Whitboards; Computer on Wheels

\section{INTRODUCTION}

The use of ICT in education and training has been a priority in most European (and not only) countries the last decade. Nevertheless the progress has not been even. On the contrary, there are great differences between countries and even between districts of the same country. A small percentage of schools in some countries have introduced ICT utilization to support the curriculum in order to transform teaching and learning among a range of subject areas. However, most of the schools in the majority of the countries are in an early phase of ICT adoption [3].

In Greece, the last 20 years many projects were implemented for the introduction of ICT in the educational system. Most of them were financing by E.C. funds within various support frameworks. The Ministry of Education, Lifelong Learning and Religious Affair ("Ministry of Education" for now on) within his strategic plan for the improvement of the education in Greece, has setup a whole action called "Digital School" (http://digitalschool.minedu.gov.gr/) for the introduction of ICT in schools (compulsory education) for the years to come.

"Digital School" represents a holistic approach with a parallel development of all the needed parameters, that knowledge and experience has declared as critical, for the successful introduction of ICT in schools. Towards this aim, a series of actions is planned and has started implementing. These actions are organized into the five main pillars:

- Reinforcement of the network and computer infrastructure of the schools targeting the creation of the "digital class". A digital class has fast Internet access, is equipped with IWB, and the teacher and students interact in a dynamic fashion through the use of those modern ICT tools.

- Rich, interactive digital education content that is matched to the curriculum for all classes and disciplines.

- Teacher education and training focused on the educational utilization of ICT.

- Integrated electronic school and educational content Management System.

- Horizontal support actions.

Two specific projects within this framework were: a) the pilot introduction of interactive whiteboards (IWB) in schools of lower secondary education and b) the introduction of computer on wheels (COWs) labs in schools of primary education.

These two pilot projects were started on August of 2010 and nowadays (May 2011) are in their final stages. The total budget for both was almost $16 \mathrm{M} €$ and more than 1,900 schools were participated. The implementation process was not smooth at all, which is not strange if you take under consideration that there were more than 1,800 tenders published from the appropriate school committees. Nevertheless the commitment of all the participants as well as the strong support of the administrative units of ministry of education seems to drive the whole action to a successful completion within a very small time period (less than 10 months). What is needed now is the evaluation of the project's result in order to realize key factors, barriers, as well as mistakes and perform thus being able to perform the appropriate interventions for the next phase which is the roll out of the pilot projects to the rest of the schools.

In this paper the main facts regarding the two pilot projects are presented, especially regarding the implementation process. Additionally, and since the projects are in their final stages the key finding up to now are discussed and certain conclusions are drawn especially on the administration/managerial level.

\section{LITERATURE REVIEW}

There is a huge number of studies, surveys and research papers in the literature regarding Information and Communication Technologies (ICT) in education. Most of them focus on the impact that ICT might have on learning and learners, either from the teacher or from the student point of view [10]. The common outcome of the majority 
them states that ICT has a positive impact on learning in general, but this impact is exclusively depended on the way that ICT is utilized within the educational system, the school, or even the classroom. Regarding IWB, the most common outcomes from the literature are: a) they are among the most adopted technologies from educators, b) they have certain technological characteristics that gives them the ability to have a positive impact on the performance of pupils/students of all grades and c) this impact is highly correlated with the way that educators introduce them and use them in the classroom.

Thus, the last 4 decades there is a continuous and raising penetration of ICT in the educational systems of different countries all around the world. One such case is the USA, where ever since the late '70ties have started to introduce computers in the classroom. Nowadays, there are many initiatives either on a state level, or from the federal government [9]. In Europe, there are analogous initiatives in most of the countries, with different approaches regarding the implementation strategy as well as the main priorities. For instance a quite interesting case is Portugal, which in 2008 started the "Magellan Initiative" (http://en.wikibooks.org/wiki/One-to-One_Laptop_Schools/ Portugal) for the purchasing of more than 500.000 laptop computers (based on Intel's classmate) for pupils.

On the other hand, the last three decades there was a number of initiatives for the design and implementation of "cheap computers" (computers for the poor) targeting mainly at the underdeveloped countries (http://www.ictworks.org/tags/computador-popular). The first such initiation was "Simputer" (Simple Inexpensive Multilingual Computer - http://www.simputer.org/) that started in 1998. About the same time in Brazil, the "Computador Popular", an analogous cheap computer was conceived. With the change of the century a number of efforts for the creation of cheap computers were started [8] with the most promising being OLPC (One Laptop per Child - http://one.laptop.org/).

Regarding IWB, and since they have not that long history as technological assets, the first initiatives were started only the last decade. Thus, from 2003 to 2005, the UK government spent more than 50 million pounds for the introduction of IWB in schools [5]. More recently, Mexico started a project for the introduction of IWB in the $5^{\text {th }}$ and $6^{\text {th }}$ grade throughout the country. In the USA and Canada, a number of states and even individual schools, have already introduce IWB: according to "Futuresource Consulting", the number of IWB that were purchased in $\mathrm{K}-12$ schools in North America raised from 256,000 in 2008 to about 319,000 in 2009. In Ireland from 2009 to 2010, the penetration of IWB in education raised from $30 \%$ to $45 \%$. Certain initiatives were also undertaken in Australia, Portugal [6] and other countries. According to the above mentioned firm, in 2009 there were almost 750,000 IWB purchased around the world, while more than 900,000 were sold in 2010. Nevertheless the total penetration of IWB in the classroom throughout the world is still rather low $(7 \%)$ and as a result, researchers expect a further raise of the IWB purchases in the years to come.
All the above mentioned paradigms are just a few among the initiatives regarding the introduction of ICT in the educational system. And all are based on the assumption that ICT can supplement the teacher and improve the educational outcome in general. Nevertheless this assumption is not commonly accepted by the researcher's community. Even worst, on the hypothetical question: "on what kind of technology should we invest in today's schools" having in mind the more or less global economic crisis that we are experiencing, does not have a commonly accepted answer. Even though researchers have "proven" that schools with good ICT resources achieve better results than those that are poorly equipped [1], there are voices who claim that investing in ICT for education might prove quite ineffective, if it is driven by just an over enthusiasm towards technology than targeting at the improvement of the educational process $[4,7]$.

As a result one can safely argue that it is not at all obvious that by introducing ICT in an educational system, the overall educational performance will improve. On the contrary, a number of other factors have to be fulfilled (support, teacher's training, content creation, etc.) and the whole initiative must be part of a coherent master plan towards the systematic improvement of an educational system [2].

In Greece the first steps of ICT introduction in the educational system started in the late ' $80 \mathrm{~s}$ with the introduction of a desktop computer in certain schools (within the MOP framework). The next steps came within $2^{\text {nd }}$ and $3^{\text {rd }}$ Community Support Framework when the school labs were introduced, each one having between 8-12 desktop computers (see "Odysseia" project - http://odyseia.cti.gr). Ever since, there were many other projects most of them under community support frameworks. Today, as it was mentioned in the previous, the ministry of education's overall strategy includes in a prominent place, the so called "digital school" which aims at achieving a better educational outcome for teachers and students, by utilizing ICT [2].

\section{PILOT PROJECTS}

Within "digital school" action, two pilot projects were initiated in 2010: the introduction of Interactive White Boards (IWB) to lower secondary education schools and the introduction of Computer on Wheels (COWs) or "mobile labs" to primary education schools. These actions, which are now in their final stage, will undergo an assessment regarding the process as well as their results and after the appropriate interventions they will be expanded in order to cover all the primary and secondary education schools.

\section{A. IWB}

In the past, there were no initiatives for the introduction of IWB coming from the central government (ministry of Education). Nevertheless, some schools had already purchased such infrastructures on an individual bases and in a very small scale. The pilot project for the introduction of IWB in secondary education school started in August 2010, within operational programme "Education and Lifelong 
Learning". It included the installation of an IWB system in all the grade 2 classrooms of lower secondary education (Gymnasio). A IWB system includes: a) the interactive whiteboard, b) the projector c) a laptop computer plus the necessary cables, and d) the appropriate services regarding the installation, set up and guarantee of all the equipment. There were five different types of IWB systems specified, in order to feet easier in the different needs of every individual school. Thus each school could select the type that was appropriate for it. More specifically the following types of IWB were identified: 1) High resistance surface, 2) Resistive - touch-based surface, 3) Electromagnetic surface, 4) Mobile and 5) Interactive projector. More than 1,200 schools participated in the project with more than 3,500 IWB systems purchased in total. The distribution of the IWB types that were purchased is shown in the table 1.

TABLE I. DISTRIBUTION OF IWB PURCHASED

\begin{tabular}{|c|c|c|}
\hline IWB Type & $\#$ & $\%$ \\
\hline TYPE 1 & 1.649 & $45.28 \%$ \\
\hline TYPE 2 & 933 & $25.62 \%$ \\
\hline TYPE 3 & 452 & $12.41 \%$ \\
\hline TYPE 4 & 157 & $4.31 \%$ \\
\hline TYPE 5 & 451 & $12.38 \%$ \\
\hline TOTAL & 3.642 & $100 \%$ \\
\hline
\end{tabular}

\section{B. COWs}

The Computers on Wheels (COWs) initiative's main target was the introduction of laptop computers in the classroom as a "mobile computer's lab". More specifically, this was a pilot action as well, for the support of 800 (all day) primary education schools ("Dimotiko") with ICT infrastructure.

Regarding the equipment, the initiative included, for every single school, the purchasing of: a) ten (10) laptop computers with dual boot operating system (Ms Windows \& Linux), b) a mobile cart for the storage, transfer and charging of the laptops, c) a wi-fi access point for the laptops to be interconnected, d) data cabling in each classroom that will connect the access point to the school's router (and thus to the Panhelenic school network) and e) the appropriate services for the installation, initialization, setup, support, etc., of the equipment.

\section{IMPLEMENTATION MECHANISM}

On Jun 9, 2010 the Special Management Authority (SMA) of Operational Programme "Education and Lifelong Learning" (http://www.edulll.gr) published the call No78 which invited School Committees to submit their proposals for the procurement of IWB's. It was the objective of this call that all Lower Secondary schools of Greece should purchase IWB's for their entire 2nd grade classes. The total budget was $9 \mathrm{M} €$.

Again on June 18, 2010 the abovementioned management authority published another call, the No80, which invited School Committees to submit their proposals for the procurement of COW's. It was the objective of this call that 800 (all day) primary schools, should purchase
COW's to be used in the classroom for the support of teaching. The total budget was $7 \mathrm{M} €$.

Both calls were implemented through the same mechanism, using the same procedures. As the final beneficiary, School Committees (SC) had to respond to the call with a formal proposal document submission. In the proposal documents the SC had to describe the type and the quantity in the case of IWB's, the person responsible for this Act and the total amount of requested budget. The SMA after evaluating the proposal awarded the requested budget to the $\mathrm{SC}$ in order to proceed to the implementation phase.

The first thing that the SC should do was to conduct a tender with sealed offers, and award the tender to the lowest bidder. The objective of the tender was the purchase of IWB's or COWs, accompanying s/w, the required structured cabling, and the relevant installation and maintenance services. Only 20 days where given to the contractors to fulfilled their obligations. After testing and proofing of the total installation, the final acceptance protocol was signed, and then send to the Authority for last check and finally the contractor was paid. The SC was also obliged to fill and send a Declaration of Act Completion document that finally from the administrative perspective - was closing the Act's life cycle.

The Special Implementation Authority for Educational Programmes (SIAEP) of the Ministry of Education was acting as an assistive mechanism to the whole act and thus to the SC, therefore providing them with all the necessary support (documents, directions, technical support, etc) and acting as a median between them and the Management Authority.

For the support, monitoring, coordination and implementation control of the whole project, a support infrastructure was deployed within the Ministry of Education. Three working groups were formed: Project, BackOffice and HelpDesk. A website was created (http://promitheies.sch.gr/) to provide SC, and all participants with information and guidance regarding the two projects. Projects' procedures and various documents were available through the website. Various technical means and tools where utilized such as: a call center, e-mail support, eticketing, a special computer application (named "phases") to monitor different stages of the project life-cycle, etc.

\section{DISCUSSION}

The pilot projects abovementioned are near their completion by now (May 2011). Thus the first results could be extracted with relevant safety especially on the implementation methodology and the procedures that were followed (for safe results regarding the pedagogical utilization of the COW's and IWB's one must wait for significant amount of time, in order to be fully utilized and integrated in the educational process).

The selected projects' implementation strategy was the utilization of the SC throughout the country (a distributed approach vs. a centralized open tender process). Judging from the results, regarding the time aspect of the implementation, it was a wise decision: In less than ten (10) months tangible results have been obtained, whereas if a 
centralized tender should have been selected, more than one year would have been required. Extra benefit from the selected strategy is the active implication and involvement of the school community (teachers and SC). As a negative aspect we could focus on the disproportional managerial overhead placed on the administrative and support mechanism. There were too many support requests that needed to be served. Four different units where utilized extensively: a) SMA, b) SIAEP, c) Information Society Bureau and d) Directorate of Programming and Operational Research, with more than 20 persons working extra time under stress to support the SCs. Additionally, this distribution in the implementation didn't provide any large scale economies regarding the total cost (CAPEX - capital expenditure) of the projects.

The projects' life-cycle was marked by many reengineering attempts mainly after the evaluation of the projects' problems, evolution in time, etc. Digitization of as many as possible, steps in the implementation process was attempted. An example is the projects' website that actually changed during implementation, from a simple informative one to multi-functional tool for the stakeholders.

On a technical level, various problems emerged regarding hardware and software specifications. Some of them were: The "ultra short throw" spec for the projector was not initially specified in details, which proved to be a point of disagreement from various companies and oblige the ministry to set a specific norm. The five different types of IWB that were specified produced more confusion than benefit, and as a result there were occasions that SCs were unable to judge whether an IWB that was offered was in the e.g. first or third category. Regarding the system software it was not clear what kind of office suite was to be offered by the bidders: The specs were open both to open source suite and to commercial (proprietary) one and many SCs were asking for further advice.

It is our belief that in any future project concerning IWB's, fewer categories should be imposed. Additionally, a mandatory pre-selection of suitable products, which would lead to the foundation of an IWB's registry, seems to be needed. Furthermore, regarding the issue of Open Software vs. Commercial one, the Ministry of Education must take the appropriate decisions. Another major issue that initiates from the distributed implementation process that was chosen, is the different types (and thus incompatible) of IWB software that were installed in schools. Although this issue might be partially solved by the adoption of certain standards, there are still discussions regarding the optimal solution. The given project duration (20 days) was proven insufficient and unrealistic. The poor implementation of certain installation (especially on cabling works) must also be mentioned, since there were occasions were contractors acted rather unprofessionally and poorly on the technical aspects of it. Last but not least is the unfortunate issue of property theft in some school regarding the equipment purchased through the projects. Certain method of overriding this problem are been taken under consideration.

\section{CONCLUSIONS}

In this paper we have reviewed the two pilot programs that targeting at the introduction of COW's to primary schools and IWB's to lower secondary schools in Greece, mainly from the procurement / administration aspect. The goal set was to record and evaluate the procedure that was selected and used for these actions in order to assist the widespread of such systems throughout the Primary and Secondary Education schools. The pedagogical utilization of the abovementioned systems which is as well important cannot be evaluated due to the limited time passed from their introduction.

We may claim that both programs were more or less successful - based on the projects' goals and priorities. Nevertheless, certain problems and dysfunctions of the whole procedure were identified which will provide useful information for a future large scale deployment of relevant systems.

The hard evidence is that 1077 School Committees have been funded for purchasing and installing IWB's to their Lower Secondary Education schools and more than 3,500 IWB's in total will be installed. Additionally 745 School Committees have been funded for purchasing and installing COW's to their Primary schools and ten times that is the total amount of laptops that will be given to Dimotiko Schools for use in the classroom.

The most important findings regarding common problems found during the projects implementation are:

- There was a lot of bureaucracy with the given number of stakeholders and that was an unbearable load indeed, but in most (?) cases this was posed by the rules of NSRF.

- The SC weren't as experienced as needed to handle such tasks posed by the NSRF.

- There were various technical issues, like misinterpreted specs, that need further clarification in the future.

- The Helpdesk's performance was a key factor to the progress and the success of the projects.

- There were delays and weaknesses posed by the local IT market related to the completion of the projects.

Finally we must have in mind, that these two pilot projects are just part of a greater strategic plan and must not be conceived as autonomous ones. They are closely related with teacher's training in IWB use (http://b-epipedo2.cti.gr/), the development of the appropriate educational software and educational content (calls No61 \& 62 of EDULLL http://www.edulll.gr/?p=992), and many other support actions. And the whole action should then be evaluated in total.

\section{REFERENCES}

[1] P. Attwell and J. Battle. "Home Computers and School Performance" Information Society, vol. 15: 1, 1998.

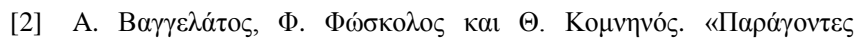

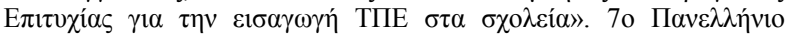

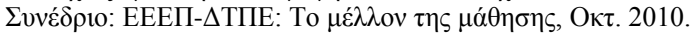


[3] A. Balanskat, R. Blamire and Kefala. "The ICT impact report: A review of studies of ICT impact on schools in Europe". European Schoolnet Project. 2006.

[4] H. Becker. "Who's wired and who's not: Children's access to and use of computer technology". Children and Computer Technology, vol. 10(2), 2000.

[5] BECTA. Evaluation of the Primary Schools Whiteboard Expansion Project. 2006. Retrieved from http://tinyurl.com/4ts2jth .

[6] M.J. Goncalves. "Interactive White Boards in Portuguese primary schools. The teachers' view". WMSCI 2010, Retrieved from http://www.iiis.org/CDs2010/CD2010SCI/SCI_2010/PapersPdf/SA88 7FI.pdf .

[7] L. Cuban. Oversold and Underused: Computers in the Classroom. Cambridge: Harvard University Press. 2001.
[8] R. Patra, J. Pal, S. Nedevschi, M. Plauche, and U. Pawar. "Usage Models of Classroom Computing in Developing Regions". Proceedings of the 2nd IEEE/ACM International Conference on Information and Communication Technologies and Development. Bangalore, India, 2007. pp 158-167.

[9] United States Department of Education. State strategies and practices for educational technology: Volume i - examining the enhancing education through technology program. 2010. Retrieved from http://www.ed.gov/rschstat/eval/tech/netts/netts-vol1.pdf.

[10] A. Winzenried, B. Dalgano and J. Tinkler. "The interactive whiteboard: A transitional technology supporting diverse teaching practices". Australasian Journal of Educational Technology, vol. 26(4), 2010. 